\title{
Correction to: Visual associative learning and olfactory preferences of the greater banded hornet, Vespa tropica
}

\author{
G. S. Balamurali ${ }^{1} \cdot$ R. S. Reshnuraj ${ }^{1}$ J. Johnson ${ }^{1} \cdot$ U. Kodandaramaiah ${ }^{1} \cdot$ H. Somanathan ${ }^{1}$
}

Published online: 22 July 2021

(c) International Union for the Study of Social Insects (IUSSI) 2021

\section{Correction to: Insectes Soc.} https://doi.org/10.1007/s00040-021-00820-w

In the publication the following two references are in the text but missing from the reference list

Jadhav JA, Sreedevi K, Rajendra Prasad P (2015) Insect pollinator diversity and abundance in sunflower ecosystem. Curr Biot 5:344-350

Wen Z, Soh W, Wen R, Ngiam J (2013) Flower-visiting bees and wasps in Singapore parks (Insecta: Hymenoptera). Nat Singapore 6:153-172

The following reference had incomplete author names

Lehrer M, Horridge GA, Zhang SW, Gadagkar R (1995) Shapevision in bees: innate preference for flower-like patterns. Philos Trans R Soc B Biol Sci 347:123-137. https://doi.org/10.1098/rstb.1995.0017

The original article has been updated.

The original article can be found online at https://doi.org/10.1007/ s00040-021-00820-w.

\footnotetext{
G. S. Balamurali

balumgs@iisertvm.ac.in

1 IISER TVM Centre for Research and Education in Ecology and Evolution (ICREEE), School of Biology, Indian Institute of Science Education and Research Thiruvananthapuram, Kerala 695551, India
} 